\title{
IMPACT OF E-MAINTENANCE OVER INDUSTRIAL PROCESSES
}

\author{
Yassine MOUMEN, Mariam BENHADOU and Abdellah HADDOUT \\ Laboratory of Industrial Management, Energy and Technology of Plastic and \\ Composites Materials Hassan II University - ENSEM Casablanca, Morocco
}

\begin{abstract}
During the course of the industrial 4.0 era, companies have been exponentially developed and have digitized almost the whole business system to stick to their performance targets and to keep or to even enlarge their market share. Maintenance function has obviously followed the trend as it's considered one of the most important processes in every enterprise as it impacts a group of the most critical performance indicators such as: cost, reliability, availability, safety and productivity. E-maintenance emerged in early 2000 and now is a common term in maintenance literature representing the digitalized side of maintenance whereby assets are monitored and controlled over the internet. According to literature, e-maintenance has a remarkable impact on maintenance KPIs and aims at ambitious objectives like zero-downtime.
\end{abstract}

\section{KEYWORDS}

E-maintenance, Maintenance, industry 4.0, industrial performance, zero-downtime.

\section{INTRODUCTION}

Maintenance has become one of the major influencers toward strategic objectives of companies in today's extremely competitive markets. Some results have shown that maintenance activities could range from $15 \%$ to $70 \%$ of the total production cost $[1,2,3]$. The cost is considered as the second largest after energy expenditures of the operational budget $[1,4,6,7]$. In the United States, the maintenance cost has tripled in 10 years to reach $\$ 600$ billion in 1989 [1]. One more important figure related to product price structure that considers maintenance operating costs value up to $28 \%$ of the product's global cost [5].

The maintenance process is a set of required activities to keep an asset at maximum availability. These activities are mainly carried out according to certain maintenance strategies [1]. In the past, maintenance had been based mainly on corrective operations. Later, maintenance became an independent function, rather than a production sub-function [1]. A decade before, as the technologies grew and systems became more complex, maintenance has been developed as well and became enclosing technical and management knowledge. Indeed, preventive maintenance, including Time Based Maintenance (TBM) and Condition Based Maintenance (CBM), has followed the Corrective Maintenance (CM) as an upgrade, Design-Out Maintenance (DOM) and Total Productive Maintenance (TPM) have arrived gradually [1].

$\mathrm{CM}$ occurred in the early industrial days spontaneously when the maintenance belonged to the production process and was also known as firefighting or emergency maintenance. CM is mainly carried out after the failure [8]. 
Contrary, the preventive maintenance which intends to reduce the probability of failure or degradation of functioning of an equipment [1,9]. Preventive maintenance is divided into TBM and CBM. TBM operations are time-based and carried out following a pre-designed schedule, rolled out by the maintenance engineering team. Whereas in the CBM, the machine's parameters are monitored using sensors like vibration, temperature and pressure. In other words, preventive maintenance operations are carried out before failure. It's also considered a double edge weapon as it prevents failure and downtime, however, some good parts are replaced though.

Design-Out Maintenance is acting proactively, by focusing on equipment design in order to eliminate the cause of maintenance. DOM makes the maintenance easier in the life cycle of a product [22]. We can even say that DOM enhances one of the most important maintenance parameters, maintainability.

Maintenance strategy choice is a crucial phase to every organisation and it has a direct impact on business results and market share. Kumar Pinjala discovered a true correlation in his empirical investigation on the relationship between business and maintenance strategies; his survey's results of 150 companies in both Belgium and the Netherlands indicated that quality competitors have more proactive maintenance policies, better planning and control systems and decentralized maintenance organisation structures when compared to others [11].

The main objective of this work is illustrate a clear image about the maintenance, how it was seen? How it looks like nowadays? What would be the e-maintenance impact? And what are the tools and means required to reach desired performance.

To answer clearly all above questions mentioned, we decided to present our work as follow: First, we are going to describe the classic form of maintenance and to explain its pejorative image as it's seen as a necessary evil which is inherent, roughly, to all production systems and wherever machines would be. By next, we are going to give an insight over maintenance key parameters, in order to be able to measure properly the maintenance function performance. Afterward, an introduction, over the new concept of e-maintenance along with e-maintenance mind-set, will be presented. Finally, we discuss e-maintenance tools as described in many papers and how they can influence industrial processes.

In the long run, this paper will help authors to select the most adequate industry 4.0 tools related to maintenance. These tools are going to have a clear and direct impact avec industrial processes.

\section{Classic Maintenance Limits and KPI'S}

Classic maintenance is every maintenance strategy as described before. In spite of the fact that maintenance is a necessity, most industrial actors are still considering maintenance as a necessary evil (without optimizing)[12]. This negative image was attributed to maintenance a long time ago, when only CM operations were carried out and maintenance teams came just to fix things when they broke, even more when things break down maintenance has failed [13].

A few decades ago, maintenance function was viewed as an inherent part of the production function and very tough to manage. As we go, this thought has changed and maintenance became an independent function. Table 1 shows maintenance timeline progression: 
Table 1. Maintenance management on time perspective [14]

\begin{tabular}{|l|l|l|}
\hline Period & Progression & How it is viewed \\
\hline $1940-1960$ & $\begin{array}{l}\text { Maintenance as a } \\
\text { production task }\end{array}$ & Necessary evil \\
\hline $1960-1980$ & $\begin{array}{l}\text { Maintenance as an } \\
\text { independent department }\end{array}$ & Technical specialization \\
\hline $1980-2000$ & Integration efforts & Profit contributor \\
\hline $2000<$ & $\begin{array}{l}\text { External and internal } \\
\text { partnership }\end{array}$ & Positive cooperation \\
\hline
\end{tabular}

It's mandatory for the maintenance to be optimal, in order to have the same objectives of organisation ones. These objectives are mainly: cost, reliability, availability, safety, productivity, quality, environment and maintainability. However, with rapid technological progress, classic maintenance is no longer able to keep these KPIs above targets. Many papers were processed in different domains such as Food industry [15], Wastewater Treatment Plant WWTP [16], Aviation [17] and General industry [18]. They all suggest moving up from classic maintenance in order to be aligned with organisation objectives.

It has been noticed that e-maintenance is encompassing many of the solutions proposed for the maintenance to take off that pejorative image and give up suffering from deficiency of understanding and respect.

\section{E-MAINTENANCE AND THE NeW WAY OF THINKING}

The new way of thinking starts by giving up looking at the maintenance as a necessary evil. Maintenance has to ensure production systems availability and functionality in order to contribute to business objectives [12]. Likewise the new thinking aims to change the maintenance role from fixing breakdowns to taking into account the product life-cycle management [19].

Among the e-maintenance roles we can identify the eco-efficiency. The eco-efficiency consists of considering the maintenance in all product life phases and not only as a set of operations during the production phase. The four product life cycle phases are as follows: product design, manufacturing and assembly, usage and finally disassembly and recycling. The objective won't be producing efficiently anymore but it will be sustaining the equipment usage as late as possible while preserving equipment characteristics in terms of its availability, reliability, safety, cost, productivity and products' quality and also maintainability [21].

B. Iung, E. Levrat, A. Crespo Marquez, H. Erbe[12] have defined maintenance objectives to each product life-cycle while maintaining the global maintenance objective which is to maintain the product conditions and expected services all along its life cycle, objectives by phase are as shown below : 
Table 2. Product life-cycle maintenance objectives.

\begin{tabular}{|l|l|}
\hline Phase & Objective \\
\hline Design Engineering & $\begin{array}{l}\text { Ensure characteristics like : } \\
\text { Maintainability, Reliability, Durability }\end{array}$ \\
\hline Manufacturing & Preserve the above characteristics \\
\hline Usage & Ensure availability, reliability \\
\hline Disassembling and recycling & Ensure the durability, circular economy \\
\hline
\end{tabular}

The concept of eco-efficiency has converted maintenance into a major strategic tool with objectives perfectly aligned with business' ones such as: product quality, increasing production capacity, reducing products cost and optimizing deadlines.

As the maintenance is contributing to the value creation during each phase of the four product's life cycle steps and thus to the whole enterprise, we can therefore talk about a maintenance value chain. This value chain must be supported at each cycle step to ensure that assigned objectives have been fulfilled properly. If all objectives are reached, then the global chain is working correctly.

The value chain aims to keep the functional level of the product and to preserve all its characteristics as well as to be in line with business objectives.

Hence, e-maintenance is a philosophy striving to go from "fail and fix" operations to "predict and prevent" strategies [13, 22, 23]. In other words, B. Iung, E. Levrat, A. Crespo Marquez, H. Erbe [12] proposed to shift from considering MTBF [Mean Time Between Failure] to MTBD [Mean Time Between Degradation].

\section{E-MainTEnANCE NeW TECHNOLOGIES IMPACT}

E-maintenance has had different definitions. The web site www.mtonline.com [12] has considered it as a network that integrates the various maintenance and reliability applications to gather and collect, then deliver asset information when needed. On the other hand, Havard has defined the e of e-maintenance by "Excellent" or "Efficient". Whereas www.deicesword.net states that e-maintenance is a maintenance management concept whereby assets are monitored and managed over the internet.

\section{... After these controversies what would be the real e-maintenance?}

E-maintenance is rolling out the principles already defined by Tele-maintenance which are added to web and data services to achieve a true definition of pro-activity or the 'connected plant'.

E-maintenance relies on Intra-Net, Extranet and Internet to processes its IN and OUT. In order to fulfil its tasks, e-maintenance uses means of communication, processing and storage [12]. IT systems play a major role to make e-maintenance tasks successful.

In this section, some technology issues related to e-maintenance will be presented:

Web services which allow universal access, connectivity and multimedia support for interactivity and interoperability [24], 
- Database and its management is also considered as a mandatory tool used in digitalization, globally and in e-maintenance specifically

- $\quad$ Transducers with "built in" Internet modules allow users to connect to internet without PC connection,

- Wireless technology gives the right to flexibility on the floor. Remote data management facilitates transmitting, monitoring and controlling via a network [26],

- New communication pathways in industry allow for more collaboration possibilities...

More specifically, M. Ghouat [28] has studied the impact of new technologies over some indicators such as the availability. Availability is considered as the machines up time, here-below the studies result:

The impact could be characterized as follow:

Important impact

Elevated impact

Normal impact

No impact

Table 3. New technologies and their impact

\begin{tabular}{|l|l|}
\hline Technologie & Impact \\
\hline Enterprise resource Planning ERP & Medium \\
\hline Manufacturing Execution Systems MES & Normal \\
\hline Business intelligence BI & No impact \\
\hline Cloud technology & Medium \\
\hline Big data analytics & No impact \\
\hline Machine to machine communication & Important \\
\hline The Internet of things IoT and data & Normal \\
\hline $\begin{array}{l}\text { Automatic Identification } \\
\text { collection }\end{array}$ & Normact \\
\hline Radio frequency identification RFID & Important \\
\hline Virtual and augmented reality & No impact \\
\hline 3D printing & Normal \\
\hline Simulation & Normal \\
\hline Cybersecurity & Normal \\
\hline Miniaturization of electronics & Normal \\
\hline Robotics, drones and nanotech & \\
\hline
\end{tabular}

\section{UPCOMING WORK}

Future work will be a survey targeting different enterprises in France and Morocco categorized as follow:

- primary sector: also known as extractive industries [raw material extraction]. This type of company can be oil extraction companies, mining companies, forestry companies or maritime companies ...

- Secondary sector: also known as manufacturing, which affects raw material processing companies into finished or semi-finished products including agri-food, textiles, steel and metallurgy, mechanical engineering and chemical industries 
- Tertiary sector: referred to as the service sector, includes companies that are active in sales, trade, finance, real estate, etc. and other non-market activities including education, care and social.

It will also cover all cross-cutting classifications of enterprises, for-profit corporations[small and medium-sized businesses and large groups], private non-profit enterprises that are linked to the social economy and also public structures. To conclude all companies regardless of their sales figures is our target.

This questionnaire will refer to the organization of the maintenance department still in the context of reducing the probability of degradation or failure of operation. It will consider the techniques of maintenance, a dozen of which have caused devastation in the world of the industry for the fluidity of the industrial maintenance of the equipment that several experts have approved. It will deal with maintenance policy, companies are considering technical-economic objectives relating to the management of the equipment so that the actors and the related services have a base. It is necessary to distinguish two levels: the overall level of the company [basic maintenance policy], and the level of equipment [adjusted maintenance policy].

The preparation of the budget and the maintenance costs will also be highlighted given the complementarity and the obligatory nature of their presence in companies.

The means of digitalisation used within companies will also be discussed in order to know and analyse the techniques and digital solutions used. Modern industrial maintenance processes are essential for reliable production.

\section{CONClusion}

E-maintenance is a philosophy and not a technique nor a platform. All industry 4.0 tools and means could be used in e-maintenance. Nevertheless, some are definitely impactful, while others aren't. Maintenance shouldn't be seen as a necessary evil but should be considered a value stream that starts and takes place even before the product's manufacturing.

Our next step will be an empirical work based on market survey. The blocs of questions will be basically around company size, maintenance department organization and the industry 4.0 tools used in maintenance field. We will try to reach the highest number of companies with different activities in two different countries who coped successfully with COVID19 pandemic: France, one of the most developed and industrial European economies, with huge consumer market and Morocco which is considered as one of the fastest growing economies in Africa and in the world with ambitious objectives and a versatile economy encompassing local and international companies.

The survey result will come soon and will refer to the current paper to complete this prior work based on literature review.

\section{ACKNOWLEDGEMENT}

We would like to express our very great appreciation to our team members for their valuable and constructive suggestions. 


\section{REFERENCES}

[1] SherifMostafaa*, JantaneeDumrakb and Hassan Soltan. Lean Maintenance Roadmap. PP 2-3Volume 51, Issue 30, 2018, Pages 800-802. https://doi.org/10.1016/j.ifacol.2018.11.192

[2] K. Fraser, 2014, Facilities management: the strategic selection of a maintenance system, Journal of Facilities Management. 12, 18-37.

[3] S.K. Pinjala, L. Pintelon, A. Vereecke, 2006, An empirical investigation on the relationship between business and maintenance strategies, International Journal of Production Economics. 104, 214-229

[4] M. Bevilacqua, M. Braglia, 2000, The analytic hierarchy process applied to maintenance strategy selection. Reliability Engineering \& System Safety. 70, 71-83.

[5] B.S. Blanchard, 1997, An enhanced approach for implementing total productive maintenance in the manufacturing environment, Journal of Quality in Maintenance Engineering. 3, 69-80.

[6] T. Santos, F. J. G. Silva*, S. F. Ramos, R. D. S. G. Campilho, L. P. Ferreira. Asset Priority Setting for Maintenance Management in the Food Industry. Volume 38, 2019, Pages 16231633.https://doi.org/10.1016/j.promfg.2020.01.122

[7] P. Neves, F. J. G. Silva, L. P. Ferreira, T. Pereira, A. Gouveia, and C. Pimentel, 2018, Implementing Lean Tools in the Manufacturing Process of Trimmings Products, Procedia Manufacturing 17 696704.

[8] Márquez, A.C., 2007, The maintenance management framework: models and methods for complex systems maintenance. Springer.

[9] M.M. Fouladgar, A. Yazdani-Chamzini, A. Lashgari, E. K. Zavadskas, Z. Turskis, 2012, Maintenance strategy selection using AHP and COPRAS under fuzzy environment, International Journal of Strategic Property Management. 16, 85-104.

[10] G.Waeyenbergh, L. Pintelon, 2004, Maintenance concept development: A case study, International Journal of Production Economics. 89, 395-405.

[11] Srinivas Kumar Pinjalaa, Liliane Pintelona,_, Ann Vereecke . An empirical investigation on the relationship betweenbusiness and maintenance strategies? Volume 104, Issue 1, November 2006, Pages 214-229. https://doi.org/10.1016/j.ijpe.2004.12.024

[12] B.Iung, E.Levrat, Crespo.Marquez, H.Erbe E-Maintenance: Principles, review and conceptual framework. Volume 40, Issue 19, 2007, Pages 18-29. https://doi.org/10.3182/20071002-MX-43906.00005

[13] Blann Dale R. (2003), Reliability as a Strategic Initiative: To Improve Manufacturing Capacity, Throughput and Profitability Asset Management \&Maintenance Journal, 16(2).

[14] Pintelon, L., Gelders, L., Van Puyvelde, F., 2000. Maintenance Management, second ed. Acco Belgium, Leuven.

[15] T. Santos, F. J. G. Silva*, S. F. Ramos, R. D. S. G. Campilho, L. P. Ferreira. Asset Priority Setting for Maintenance Management in the Food Industry. Volume 38, 2019, Pages 1623-1633. https://doi.org/10.1016/j.promfg.2020.01.122

[16] Vicent Hernández-Chover*, Lledó Castellet-Viciano, Francesc Hernández-Sancho. Preventive maintenance versus cost of repairs in asset management: An efficiency analysis in wastewater treatment plants. Volume 141, September 2020, Pages 215-221 https://doi.org/10.1016/j.psep.2020.04.035

[17] Tseko Mofokeng, Paul T Mativenga, Annlizé Marnewick. Analysis of aircraft maintenance processes and cost. Volume 90, 2020, Pages 467-472. https://doi.org/10.1016/j.procir.2020.01.115

[18] Xh Mehmeti, B Mehmeti, Rr Sejdiu . The equipment maintenance management in manufacturing enterprises. Volume 51, Issue 30, 2018, Pages 800-802. https://doi.org/10.1016/j.ifacol.2018.11.192

[19] Takata S., F. Kimura, F.J.A.M. van Houten, E. Westkämper, M. Shpitalni, D. Ceglarek, J. Lee(2004), Maintenance: Changing Role in Life Cycle Management, Annals of the CIRP, 53/2, pp 643 - 656

[20] Van Houten F.J.A.M., Tomiyama T., Salomons O.W., (1998), Product modelling for model-based maintenance, Annals of the CIRP, 47/1, pp123-129

[21] DeSimone, L. D., Popoff, F. with the WBCSD (1997), Eco-Efficiency, MIT Press.

[22] Lee J., J. Ni, D. Djurdjanovic, H. Qiu and H. Liao (2006), intelligent prognostics tools and emaintenance, Computers in Industry, Special issue on e-maintenance, 57(6), pp 476-489

[23] Iung B., Morel G., Léger J.B. (2003) Proactive maintenance strategy for harbor crane operation improvement, Robotica, Special issue on Cost Effective Automation, Eds H. Erbe, 21(3), pp.313-324.

[24] Lee J. (1998). Teleservice engineering in manufacturing: challenges and opportunities. Int. Journal of Machine Tools \& Manufacture. 38, pp 901-910. 
[25] Wang, J., Tse, P., He, L.S. and R. Yeung (2004). Remote sensing, diagnosis and collaborative maintenance with Web-enabled virtual instruments and mini-servers. International Journal of Advanced Manufacturing Technology, 24(9-10), pp. $764-772$.

[26] Egea-Lopez E., Martinez-Sala A., Vales-Alonso J., Garcia-Haro J. and Malgosa-Sanahuja J-M. (2005). Wireless communications deployment in industry: a review of issues, options and technologies. Computers in Industry, 56 (1), January, pp. 29-53.

[27] M. Ghouat A. Haddout, M. Benhadou. Impact of industry 4.0 concept on the levers of Lean Manufacturing approach in manufacturing industries. International journal of automotive and mechanical engineering (IJAME). ISSN: 2229-8649 e-ISSN: 2180-1606 VOL. 18, ISSUE 1, $8523-$ 8530 DOI: https://doi.org/10.15282/ijame.18.1.2021.11.0646

\section{AUTHOR}

Yassine MOUMEN, 28 November 1990, Engineer in maintenance

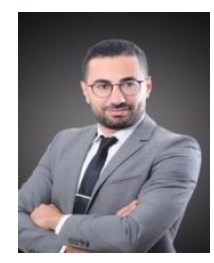

(C) 2021 By AIRCC Publishing Corporation. This article is published under the Creative Commons Attribution (CC BY) license. 